\title{
The Characterization of HIP and RHIP Consolidated NiAl Intermetallic compounds Containing Chromium Particles
}

\author{
Shintaro Ishiyama ${ }^{1}$, Hans Peter Buchkremer ${ }^{2}$ and Dovert Stöver ${ }^{2}$ \\ ${ }^{1}$ Japan Atomic Research Institute, Tokai-mura, Naka-gun, Ibaraki 319-11, Japan \\ ${ }^{2}$ Institute of Energy Materials 2(IWE2), Research Center Jülich, Germany
}

$\mathrm{NiAl}$ intermetallics with dispersive Cr particles consolidated by the Hot Isostaic Press (HIP) and Reactive HIP (RHIP) techniques, has been investigated. Mechanical properties of HIPed and RHIPed materials with various $\mathrm{Cr}$ concentrations ranging form 0 to 30 mass $\% \mathrm{Cr}$, were

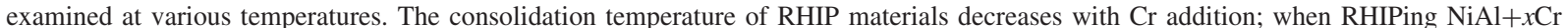
compounds with 25 mass \% has attained remarkable high ductility over $17 \%$ elongation and over $400 \mathrm{MPa}$ tensile strength at $873 \mathrm{~K}$. A very high tensile strength of HIPed $\mathrm{NiAl}+20$ mass $\% \mathrm{Cr}$ over $600 \mathrm{MPa}$ with $10 \%$ elongation at $873 \mathrm{~K}$ can be achieved at $873 \mathrm{~K}$.

(Received October 7, 2002; Accepted February 21, 2003)

Keywords: NiAl Intermetallic compound, chromium, hot isostatic press, reactive hot isostatic press, tensile strength, ductility, ductile brittle transition temperature

\section{Introduction}

The Intermetallic compound $\mathrm{NiAl}$ is one of the most promising candidate materials with lightweight, high melting point and oxidation-resistance. It has a potential for lightweight and high temperature structural materials such as helium gas turbine for $600 \mathrm{MWt}$ HTGR-GT system, in which a single turbine and compressor rotor shaft has a weight limit in its design due to rotor dynamics and lift-up capacity limit of magnet bearing on the service. ${ }^{1-3)}$ However, its lower temperature ductility and high creep rates limit the practical use of NiAl. A lot of works have been done to improve these weak points. ${ }^{4-13)}$ In recent years, significant improvements of ductility were reported. ${ }^{4-8)}$ Various techniques were also developed to improve the high temperature strength. ${ }^{9-15)}$ However, their effects on mechanical properties of $\mathrm{NiAl}$ materials at elevated temperature have only been investigated to a limited extent.

Hot Isostatic Press (HIP) and Reactive HIP (RHIP) techniques have the advantages in minimizing micro-segregation and contamination of the elemental powders at its consolidated process, and in achieving small grain size of $\mathrm{NiAl}$ matrix with the solid solubility of the ternary additions. These advantages are expected to improve low temperature ductility and high temperature strength of NiAl intermetallics.

The purpose of the present study aims for improvement of low temperature ductility and strength of $\mathrm{NiAl}$ intermetallic compound by adding $\mathrm{Cr}$ addition and its consolidation by HIP and RHIP techniques.

\section{Experimental Procedure}

\subsection{Materials}

Both $\mathrm{Ni}+\mathrm{Al}(1: 1)$ elemental mixed powder and NiAl prealloyed powder with mixing addition of chromium powder were prepared in the present study. $\mathrm{Ni}$ (mean particle size, $7 \mu \mathrm{m} 3600 \mathrm{mesh}$ ) and $\mathrm{Al}$ elemental powders(mean particle size, $20 \mu \mathrm{m} 635 \mathrm{mesh}$ ) are supplied by VALKO WERKSTOFF TECHNOLOGGIE GMBH(Germany) and H.C. Starch
Table 1 Chemical compositions and impurity levels of as-received NiAl pre-alloyed powder.

\begin{tabular}{ccccccc}
\hline $\mathbf{C}$ & Al & $\mathbf{B}$ & $\begin{array}{c}\text { Si } \\
(\mathbf{m a s s} \%)\end{array}$ & $\mathbf{S}$ & $\mathbf{O}$ & $\mathbf{N i}$ \\
\hline 0.02 & 30.3 & 0.12 & 0.06 & $<0.01$ & 0.04 & Bal. \\
\hline
\end{tabular}

GMBH(Germany), respectively. A coarse Cr powder (particle size $>150 \mu \mathrm{m}$ ) was grained using mechanical alloying before mixing with the starting powders. The chemical composition and impurity levels of as-received NiAl prealloyed powder are listed in Table 1 .

The content rate of $\mathrm{Cr}$ in the powders are changed from 0 mass $\%$ to 30 mass $\%$ by 5 mass $\%$ step and seven compositions of the powders of $\mathrm{NiA}+x \mathrm{Cr}$ and $\mathrm{Ni}+\mathrm{Al}+x \mathrm{Cr}$ are prepared. The compositions of the powders used in present experiment are listed in Table 2.

\subsection{Hipping procedures}

These mixed powders were filled in stainless steel cans of $14 \mathrm{~mm}$ diameter, $2 \mathrm{~mm}$ thick, $20 \mathrm{~mm}$ long and stainless steel tubes of $14 \mathrm{~mm}$ in diameter, $2 \mathrm{~mm}$ thick, and $600 \mathrm{~mm}$ long. These capsules were evacuated at heated for out gassing at $673 \mathrm{~K}-6 \mathrm{~h}$ prior to HIP. After evacuation, every sample was encapsulated and then consolidated by HIP equipment.

Reactive HIP (RHIP) process in present study is defined as reaction process between elemental $\mathrm{Ni}$ and $\mathrm{Al}$ powers capsulated in the capsule above-mentioned during HIP procedure. RHIP technique of $\mathrm{NiAl}$ compound has the advantages in minimizing contamination of the elemental powders and consolidation process, and in obtaining small grain size and the solid solubility of the ternary element, such as $\mathrm{Cr}$.

HIP and RHIP consolidation of $\mathrm{NiAl}+x \mathrm{Cr}$ powders and $\mathrm{Ni}+\mathrm{Al}+x \mathrm{Cr}$ powders were performed in the following ways. Pattern (a); heated up by $0.25 \mathrm{~K} / \mathrm{s}$ and holded at $1523 \mathrm{~K}$ with $172 \mathrm{MPa}$ for $4 \mathrm{~h}$, Pattern (b); heated up to $973 \mathrm{~K}$ by $0.25 \mathrm{~K} / \mathrm{s}$ and hold for $900 \mathrm{~s}$ or Pattern (c); raised temperature by $0.02 \mathrm{~K} / \mathrm{s}$ from 723 to $873 \mathrm{~K}$, then raised up to $1523 \mathrm{~K}$ and 
Table 2 The composition of pre-alloyed and elemental powders with $\mathrm{Cr}$ additions; (a) Pre-alloyed powder compositions and (b) Elemental powder compositions.

(a)

\begin{tabular}{ccc}
\hline $\begin{array}{c}\text { Pre-alloyed powder compositions } \\
(\text { mass } \%)\end{array}$ & NiAl & $\mathrm{Cr}$ \\
\hline $\mathrm{NiAl}$ & 100 & 0 \\
$\mathrm{NiAl}+5 \mathrm{Cr}$ & 95 & 5 \\
$\mathrm{NiAl}+10 \mathrm{Cr}$ & 90 & 10 \\
$\mathrm{NiAl}+15 \mathrm{Cr}$ & 85 & 15 \\
$\mathrm{NiAl}+20 \mathrm{Cr}$ & 80 & 20 \\
$\mathrm{NiAl}+25 \mathrm{Cr}$ & 75 & 25 \\
$\mathrm{NiAl}+30 \mathrm{Cr}$ & 70 & 30
\end{tabular}

(b)

\begin{tabular}{cccc}
\hline $\begin{array}{c}\text { Elemental powder compositions } \\
(\text { mass\% })\end{array}$ & $\mathrm{NiAl}$ & $\mathrm{Al}$ & $\mathrm{Cr}$ \\
\hline $\mathrm{NiAl}$ & 68.5 & 31.5 & 0 \\
$\mathrm{NiAl}+5 \mathrm{Cr}$ & 66.1 & 28.9 & 5 \\
$\mathrm{NiAl}+10 \mathrm{Cr}$ & 61.7 & 28.9 & 10 \\
$\mathrm{NiAl}+15 \mathrm{Cr}$ & 58.3 & 26.7 & 15 \\
$\mathrm{NiAl}+20 \mathrm{Cr}$ & 54.8 & 25.2 & 20 \\
$\mathrm{NiAl}+25 \mathrm{Cr}$ & 51.4 & 23.6 & 25 \\
$\mathrm{NiAl}+30 \mathrm{Cr}$ & 48.0 & 22.0 & 30 \\
\hline
\end{tabular}

holded with $172 \mathrm{MPa}$ for $4 \mathrm{~h}$. These hipping schedules are summarized in Fig. 1.

Prior to HIPing experiments of $\mathrm{Ni}+\mathrm{Al}+x \mathrm{Cr}$ powders, these powders are CIPed (= Cold Isostatic Press) by $300 \mathrm{MPa}$ for $900 \mathrm{~s}$, then machined to the bar specimens $(13 \mathrm{~mm}$ diameter with $18 \mathrm{~mm}$ or $500 \mathrm{~mm}$ in length) for encapsulation in the above-mentioned cans and tubes.

A HIP dilatometer technique ${ }^{14)}$ has been employed to measure the time dependent densification behavior of these intermetallics.

\subsection{Strength tests}

Tensile tests were performed at elevated temperatures up to $1073 \mathrm{~K}$ using an Instron type testing machine under controlled head speed. Strain rate was $3 \times 10^{-4} \mathrm{~s}^{-1}$ at the strength test. Tensile specimens were machined from HIPed specimens into cylindrical test pieces with a gauge length of $17.6 \mathrm{~mm}$ and a diameter of $4.5 \mathrm{~mm}$.

Microstructure of the consolidated intermetallics was studied by optical microscopy and energy dispersive spectroscopy(EDS). Metallographic specimens were prepared by mechanical polishing and chemical etching.

Vicker's hardness measurements were made on polished surface of the specimens cut from HIPed tubes or canned materials.

\section{Results}

\subsection{HIPping tests}

Prior to RHIP, CIPed $\mathrm{Ni}+\mathrm{Al}+x \mathrm{Cr}$ elemental powders with 10,15 and 30 mass $\% \mathrm{Cr}$ are heated up to $1523 \mathrm{~K}$ in vacuum to define reactive temperature during RHIPing. Vacuum levels of farness was measured at elevating temperatures and it was

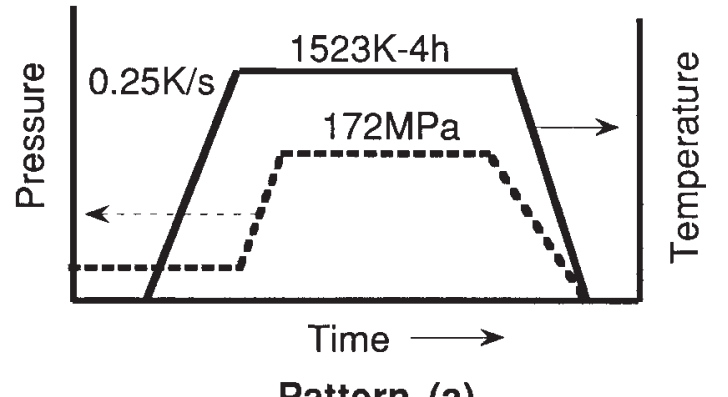

Pattern (a)

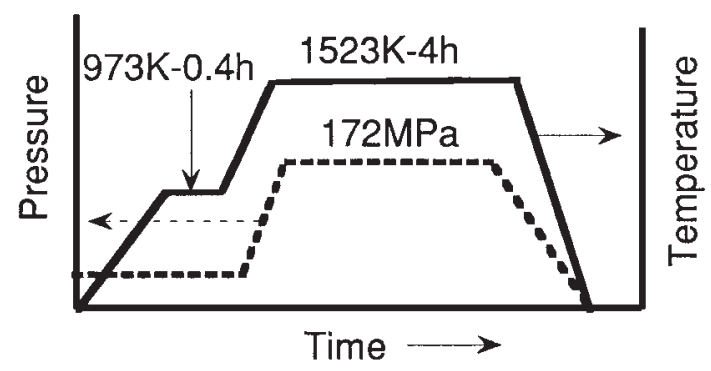

Pattern (b)

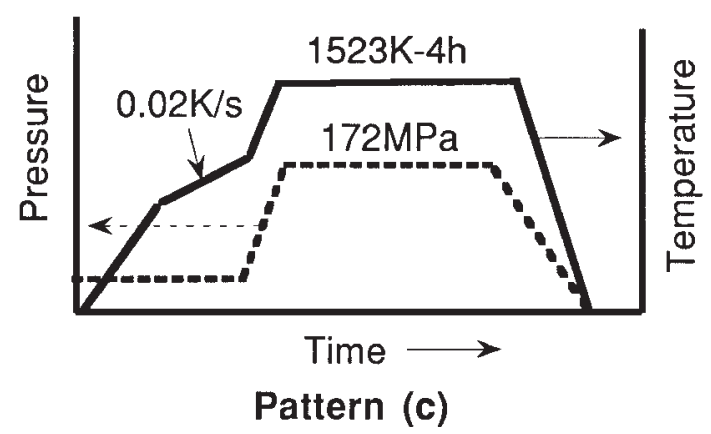

Fig. 1 HIP and RHIP schedules of $\mathrm{Cr}$ containing NiAl powders; Pattern (a) heated up by $0.25 \mathrm{~K} / \mathrm{s}$ and holded at $1523 \mathrm{~K}$ with $172 \mathrm{MPa}$ for $4 \mathrm{~h}$, Pattern (b) heated up to $973 \mathrm{~K}$ by $0.25 \mathrm{~K} / \mathrm{s}$ and holded for $900 \mathrm{~s}$ and Pattern (c) raised temperature by $0.02 \mathrm{~K} / \mathrm{s}$ from $723 \mathrm{~K}$ to $873 \mathrm{~K}$, then raised up to $1523 \mathrm{~K}$ and holded with the pressure of $172 \mathrm{MPa}$ for $4 \mathrm{~h}$.

found that the disturbed points of vacuum level due to reaction between $\mathrm{Ni}+\mathrm{Al}$ powers are observed at 838,853 and $883 \mathrm{~K}$ corresponding to $\mathrm{Cr}$ contents of 10,15 and 30 mass $\% \mathrm{Cr}$, respectively. These results indicated that the reaction temperature of $\mathrm{Ni}+\mathrm{Al}$ powders are increased as increase of $\mathrm{Cr}$ contents in these powders. With these results, the first holding cycle at $973 \mathrm{~K}$ or every slow heating rate in the reactive HIPing schedule of (b) and (c) was decided in RHIP process, avoiding irregular re-heating due to the reaction with $\mathrm{Ni}$ and $\mathrm{Al}$ elemental powder under these temperatures.

HIPed specimens of pre-alloy and elemental powders were machined and measured the relative density. A fully density was achieved by the above-mentioned hipping schedules for all these materials, however, the long tubes of the elemental mixed powder with less than 20 mass $\% \mathrm{Cr}$ were destroyed during hipping, whereas good as-hipped samples were obtained with the powder of more than 20 mass $\% \mathrm{Cr}$. 

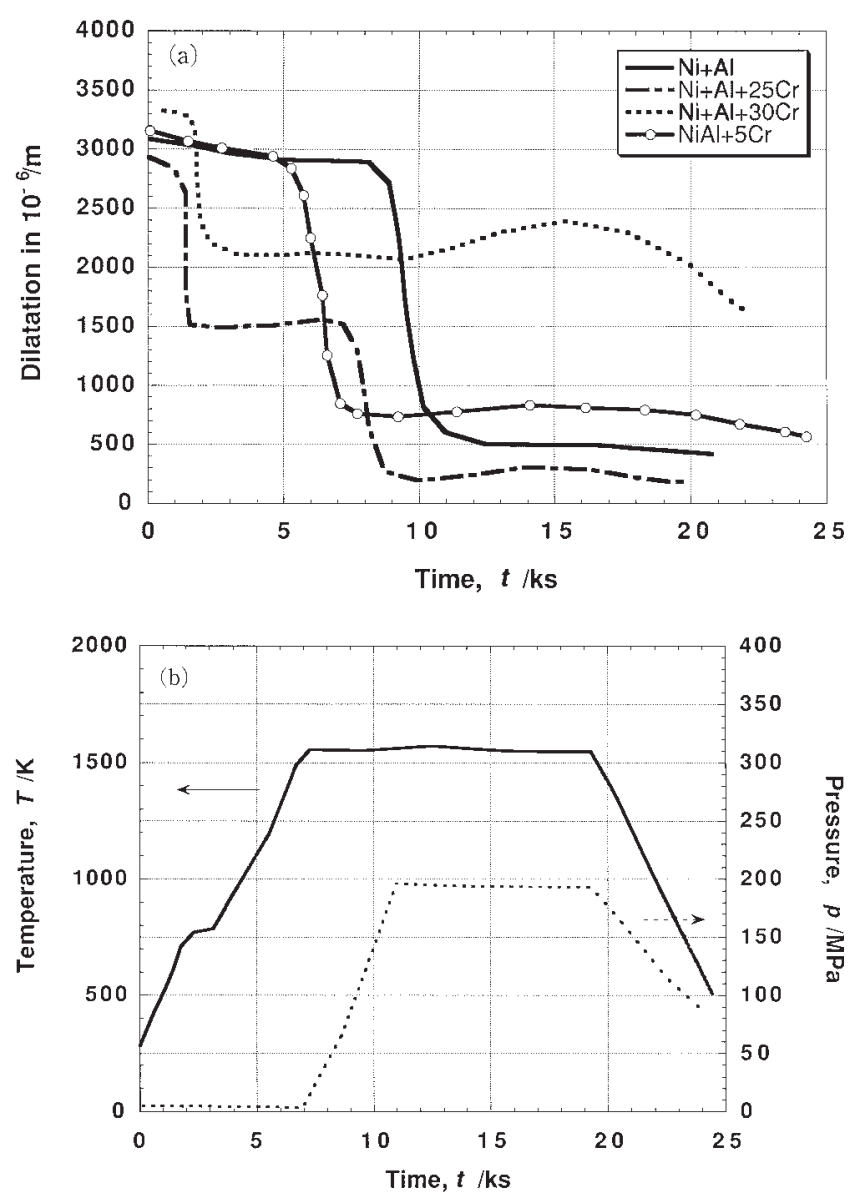

Fig. 2 Densification process of RHIPed and $\mathrm{HIPed} \mathrm{NiAl}+x \mathrm{Cr}$; (a) Shrinkage of canned $\mathrm{Ni}+\mathrm{Al}+x \mathrm{Cr}$ and $\mathrm{NiAl}+x \mathrm{Cr}$ powders and (b) temperature and pressure change in HIP process.

\subsection{Densification process}

Figure 2 shows the typical HIP and densification processes of $\mathrm{Ni}+\mathrm{Al}$ elemental mixed powders with 0,25 and 30 mass $\% \mathrm{Cr}$ and pre-alloyed powders of $\mathrm{NiAl}+5 \mathrm{Cr}$ under the HIPing. In Fig. 2(a), these lines are the length change of the canned specimen measured by the dilatometer system. A drastic shrinkage of $\mathrm{Ni}+\mathrm{Al}$ powder mainly occurred at the temperature between $1273-1473 \mathrm{~K}$, and of $\mathrm{Ni}+\mathrm{Al}$, $\mathrm{Ni}+\mathrm{Al}+15 \mathrm{Cr}$ and $\mathrm{Ni}+\mathrm{Al}+30 \mathrm{Cr}$ powders were observed at the temperature between 1373 and $1473 \mathrm{C}$. Two-step changes was found between $873 \mathrm{~K}$ and $973 \mathrm{~K}$, and $1273 \mathrm{~K}$ and $1473 \mathrm{~K}$ in the case of $\mathrm{Ni}+\mathrm{Al}+25 \mathrm{Cr}$ powder. These results indicate that the $\mathrm{Cr}$ content in $\mathrm{Ni}+\mathrm{Al}$ powder has influence reactive behavior between $\mathrm{Ni}$ and $\mathrm{Al}$ elemental powers, that is, the reactive temperature decreases as $\mathrm{Cr}$ content in $\mathrm{Ni}+\mathrm{Al}$ powder.

\subsection{Microstructure of HIPed materials}

Microstructure of the as-hipped $\mathrm{NiAl}$ pre-alloy and elemental mixed powders with $\mathrm{Cr}$ particle is complicated. $\mathrm{NiAl}$ pre-alloyed powder in present experiment essentially consists of metastable ordered matrix structure with dispersive $\mathrm{Cr}$ particles. $\mathrm{Ni}+\mathrm{Al}$ elemental powder consists of a super-saturated $\mathrm{Cr}$ concentration matrix has the non-equilibrium solidification with dispersive $\mathrm{Cr}$ particles. The microstructure involved a change in characteristic microstructure
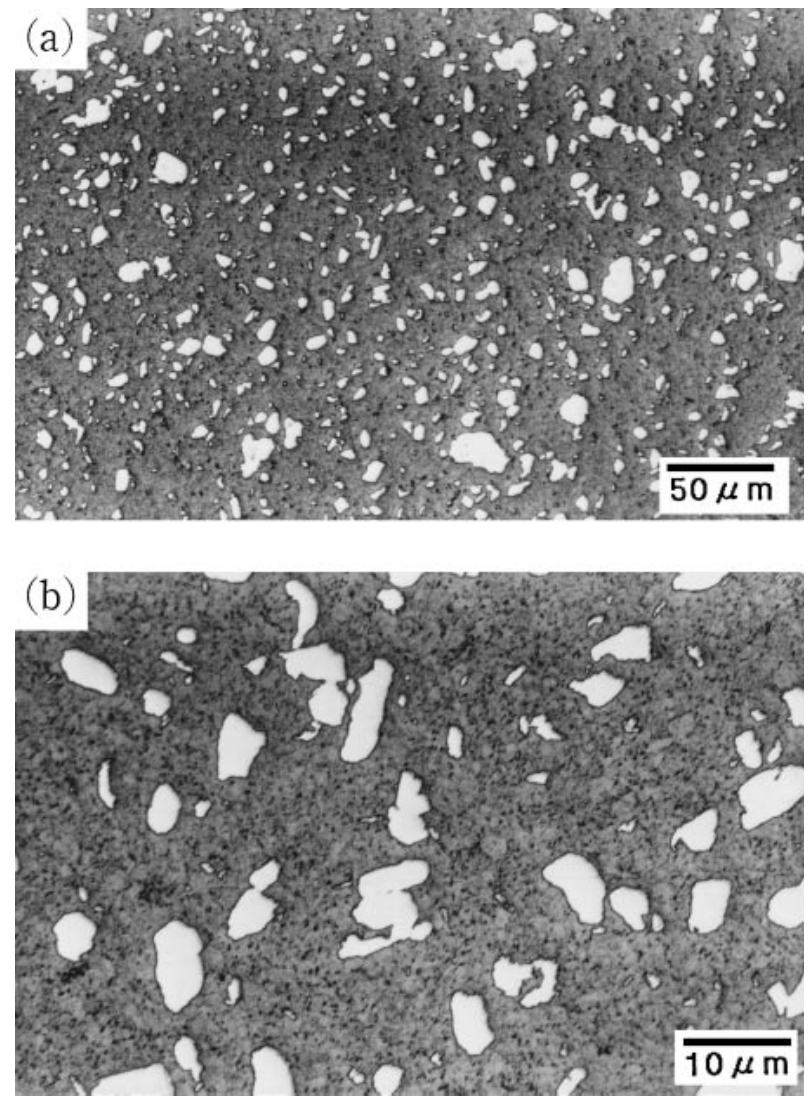

Fig. 3 Microstructure of $\mathrm{HIPed} \mathrm{NiAl}+25 \mathrm{Cr}$; (a) Macroscopic and (b) microscopic photos.

from homogeneous to inhomogeneous structure.

The dependence of microstructure development on HIPed $\mathrm{NiAl}+25 \mathrm{Cr}$ pre-alloy material is shown in Fig. 3. Each individual particle of $\mathrm{NiAl}$ and dispersive $\mathrm{Cr}$ particle remains its own identity and characteristic microstructure after HIPing. Microstructure of the as-hipped pre-alloy powder, as shown in the figure, is homogeneous with fine-grained structure (mean grain size $<35 \mu \mathrm{m}$ ). Population of $\mathrm{Cr}$ particles in matrix structure becomes higher and uniformly disturbed in matrix microstructure are in progress as increasing $\mathrm{Cr}$ additions. No reaction zone between original powder and $\mathrm{Cr}$ particle is observed in interparticle.

The microstructure of RHIPed elemental $\mathrm{Ni}+\mathrm{Al}$ powder with 30 mass\% Cr addition is shown in Fig. 4. A general view of microstructure of elemental materials is quite different from that observed in the $25 \mathrm{Cr}$ pre-alloy, as shown in Fig. 3. Homogeneous and well-developed eutectic network microstructure, which provides a very fine substructure size, is achieved in elemental materials.

\subsection{Tensile tests}

Tensile properties of the as-hipped pre-alloy and elemental materials at elevated temperatures of R.T. to $873 \mathrm{~K}$ are studied. The effect of $\mathrm{Cr}$ addition on the high temperature mechanical properties of the consolidated NiAl pre-alloy materials is shown in Fig. 5. In the figure, the stress-strain curves of as-hipped pre-alloy $\mathrm{NiAl}+x \mathrm{Cr}$ materials $(x+10-$ 30 mass $\%$ ) tested at the temperature ranging from room temperature (R.T.) to $873 \mathrm{~K}$ are shown. From these results, 

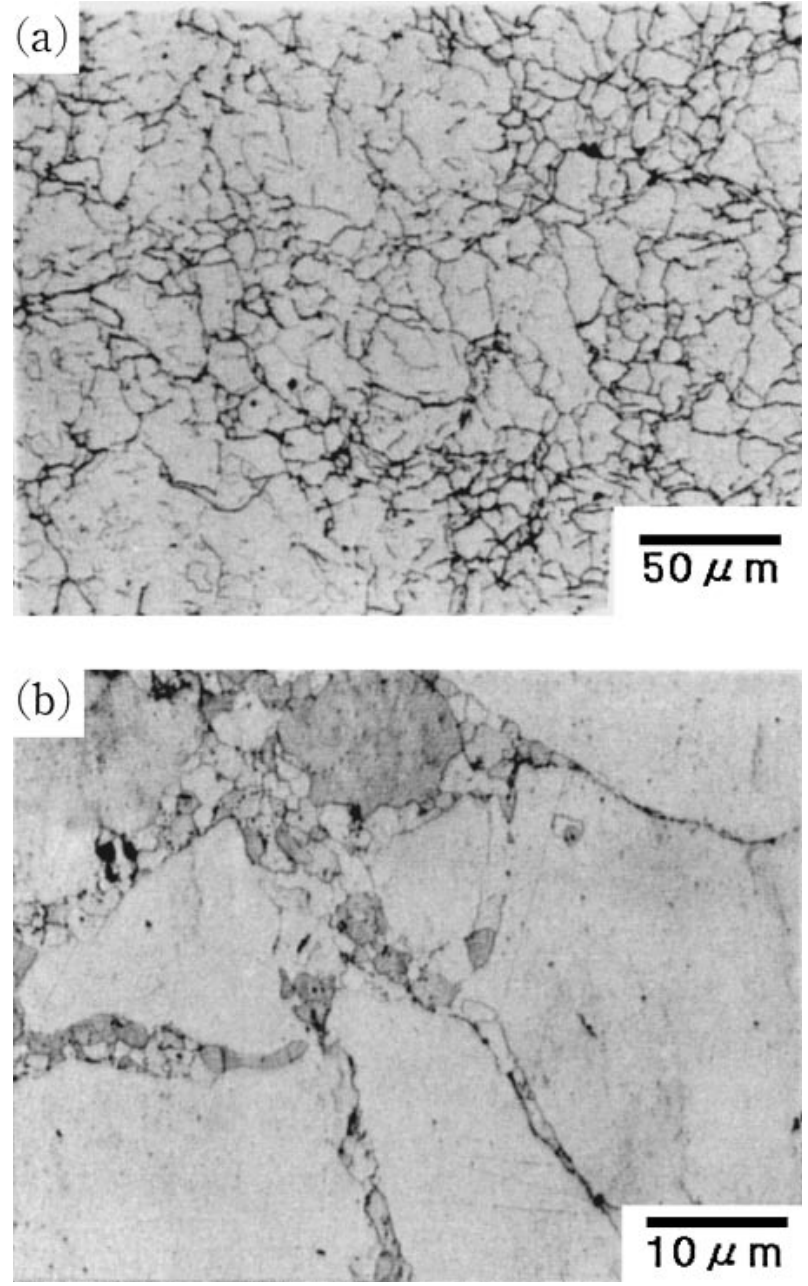

Fig. 4 Microstructure of $\mathrm{RHIPed} \mathrm{Ni}+\mathrm{Al}+30 \mathrm{Cr}$; (a) Macroscopic and (b) Microscopic photos.

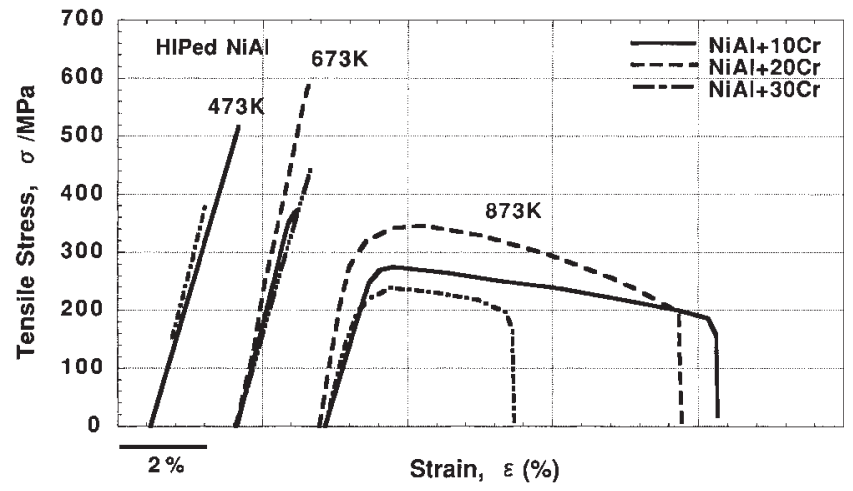

Fig. 5 Tensile stress and strain curves of HIPed $\mathrm{NiAl}+x \mathrm{Cr}$ tested at elevated temperatures.

tensile strength of these material decreased as increase of testing temperature and favorable elongation of these materials are observed at $873 \mathrm{~K}$, but the ductility is very poor at $673 \mathrm{~K}$. A very high strength can be obtained in $\mathrm{NiAl}+20 \mathrm{Cr}$ pre-alloyed material; tensile strength of about $600 \mathrm{MPa}$ at $673 \mathrm{~K}$ and more than $300 \mathrm{MPa}$ at $873 \mathrm{~K}$.

Figure 6 shows the stress-strain curves of $\mathrm{Ni}+\mathrm{Al}+25$ and $30 \mathrm{Cr}$ elemental materials and $\mathrm{NiAl}+25 \mathrm{Cr}$ pre-alloys. Comparing to the results of $\mathrm{NiAl}+25 \mathrm{Cr}$ pre-alloy, a very

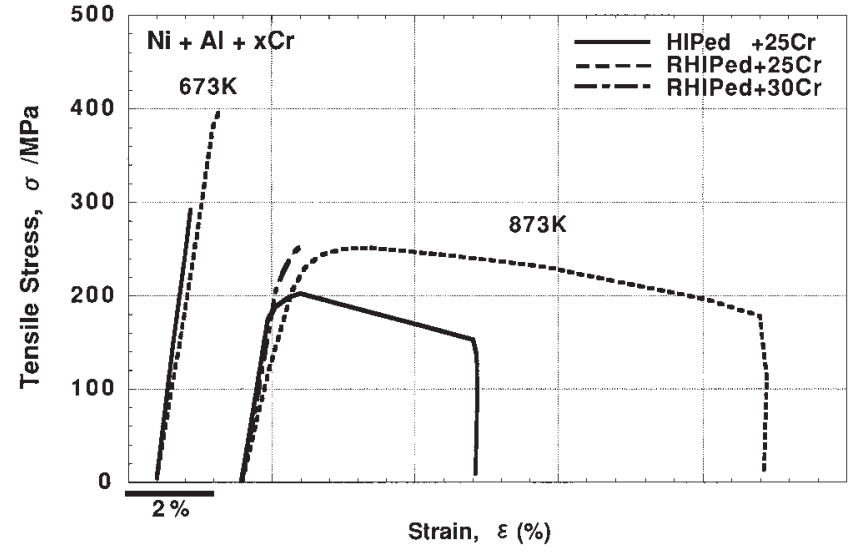

Fig. 6 Tensile stress and strain curves of RHIPed $\mathrm{Ni}+\mathrm{Al}+x \mathrm{Cr}$ tested at elevated temperatures.

high tensile ductility of elemental $\mathrm{Ni}+\mathrm{Al}+25 \mathrm{Cr}$ is observed at $873 \mathrm{~K}$, while the $\mathrm{Ni}+\mathrm{Al}+30 \mathrm{Cr}$ elemental alloy has a very low tensile ductility.

\section{Discussion}

\subsection{The effect of $\mathrm{Cr}$ additions on high temperature tensile strength}

Figure 7 show the tensile strength of HIPed pre-alloyed and RHIPed elemental materials as a function of tested temperatures. For the HIPed pre-alloyed material with between 10 and 20 mass $\% \mathrm{Cr}$ additions, tensile strength was decreased and HIPed $\mathrm{NiAl}+20$ mass $\% \mathrm{Cr}$ exhibited peak strength at the temperatures of $673 \mathrm{~K}$ and $873 \mathrm{~K}$. Whereas that of the material with more than 20 mass $\% \mathrm{Cr}$ was decreased with increasing of $\mathrm{Cr}$ concentration. The tensile strength of RHIPed elemental materials was also decreased with $\mathrm{Cr}$ additions.

The tensile strength of forged $\mathrm{NiAl}$ eutectic alloys in Ref. 15) at the temperature of $673 \mathrm{~K}$ and $873 \mathrm{~K}$ are also plotted in Fig. 7. This kind of experiments has been performed to testify the improvement of lower temperature ductility by ternary additives, as boron and another elements. ${ }^{15)}$ These forged eutectic NiAl materials with fine grain (grain size $=3 \mu \mathrm{m}$ ), in which grain size can not identified due

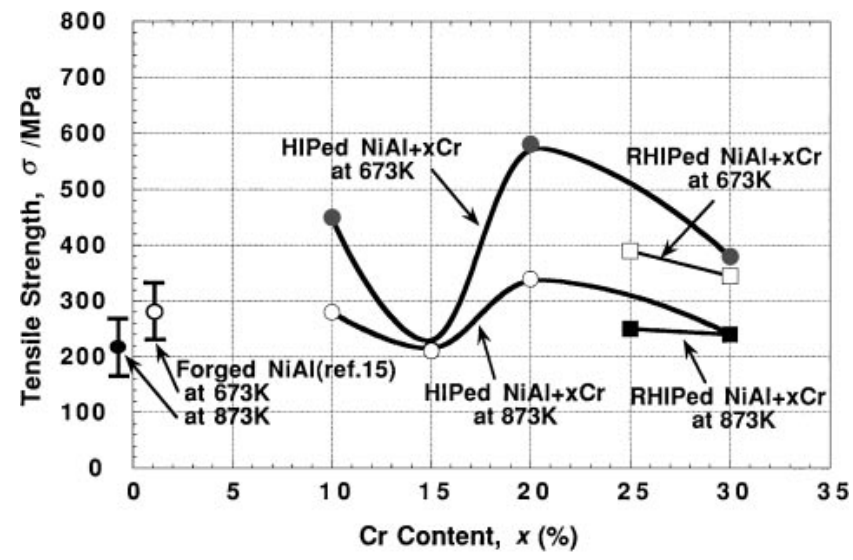

Fig. 7 Dependency of tensile strength of HIP and RHIPed $\mathrm{NiAl}+x \mathrm{Cr}$ on $\mathrm{Cr}$ addition as a function of testing temperature. 
Table 3 Hardness and elongation of HIPed and RHIPed $\mathrm{NiAl}+x \mathrm{Cr}$ obtained at $673 \mathrm{~K}$ and $873 \mathrm{~K}$.

\begin{tabular}{|c|c|c|c|c|}
\hline \multirow{2}{*}{$\begin{array}{l}\text { Cr content } \\
(\text { mass } \%)\end{array}$} & \multicolumn{2}{|c|}{$\begin{array}{l}\text { Hardness } \\
\text { (HV) }\end{array}$} & \multicolumn{2}{|c|}{$\begin{array}{c}\text { Tensile elongation } \\
\qquad(\%)\end{array}$} \\
\hline & Matrix & Particle & $673 \mathrm{~K}$ & $873 \mathrm{~K}$ \\
\hline $\begin{array}{c}0 \\
\text { (Forged NiAl) } \\
\text { Ref. 15) }\end{array}$ & 318 & - - - - & 3.4 & 8.2 \\
\hline 5 & 409 & 353 & - . - & $\ldots$ \\
\hline 10 & 472 & 281 & 0 & 12.3 \\
\hline 15 & 393 & 399 & 0 & 6.7 \\
\hline 20 & 452 & 481 & 0.4 & 10.2 \\
\hline 25 & 432 & 356 & 0 & 7.6 \\
\hline 25(RHIP) & - - - - & - - - - & 0.3 & 17.4 \\
\hline 30 & 461 & 397 & 0.1 & 4.3 \\
\hline 30(RHIP) & 503 & 372 & 0.3 & 0.8 \\
\hline
\end{tabular}

to the very complicated microstructure, are fabricated by electron beam melting method and forging technique. ${ }^{15)}$ These results indicated that tensile strength of dispersive $\mathrm{Cr}$ containing HIPed and RHIPed NiAl is superior to that of forged eutectic alloys at high temperatures, and comparing to the data of forged $\mathrm{NiAl}$ eutectic material with fine grain, structural reinforcement effect of dispersive $\mathrm{Cr}$ particle on $\mathrm{NiAl}$ matrix is clear.

Micro hardness of $\mathrm{NiAl}$ matrix and dispersive $\mathrm{Cr}$ particle in HIP and RHIPed NiAl+Cr materials listed in Table 3. From the results, it is found that matrix hardning in HIPed
$\mathrm{NiAl}+\mathrm{Cr}$ materials occurred due to $\mathrm{Cr}$ particle addition and $\mathrm{NiAl}$ matrix hardness increases with increasing $\mathrm{Cr}$ addition and exhibits higher value than that of $\mathrm{Cr}$ particle in the case of $\mathrm{Cr}$ content less than 15 mass\%. Whereas micro harness of $\mathrm{Cr}$ particle becomes larger than $\mathrm{NiAl}$ matrix in the case between 15 and 20 mass\% $\mathrm{Cr}$, and peak value of $\mathrm{Cr}$ particle was found in HIPed $\mathrm{NiAl}+20 \mathrm{Cr}$ material. However, micro hardness of $\mathrm{Cr}$ particle becomes lower than that of $\mathrm{NiAl}$ matrix again, but increases with $\mathrm{Cr}$ addition in the case of $\mathrm{Cr}$ addition more than 25 mass $\%$.

With these results, it is found that change in $\mathrm{NiAl}$ matrix hardness of HIPed $\mathrm{NiAl}+\mathrm{Cr}$ materials corresponds with the high temperature strength shown in Fig. 7. The reason why the HIPed dispersive $\mathrm{Cr}$ containing materials shows the higher strength, especially in the case of HIPed NiAl+20Cr is mainly due to its interparticle bonding and well harmonized mechanical properties between dispersive $\mathrm{Cr}$ particles and NiAl matrix.

From the SEM fractography examination of HIPed $\mathrm{NiAl}+10 \mathrm{Cr}$ and $20 \mathrm{Cr}$ materials tested at $673 \mathrm{~K}$ and $873 \mathrm{~K}$, a mixed fracture feature of interparticle and transparticle fracture morphology with large spherical shape of $\mathrm{Cr}$ particles are observed both materials tested at $673 \mathrm{~K}$, as shown in Figs. 8(a) and 9(a). The area fraction of transparticle fracture in these materials increased with increasing $\mathrm{Cr}$ additions, but in the $10 \mathrm{Cr}$ material tested at $873 \mathrm{~K}$ (Fig. 8(b)), only a fully matrix fracture is found. Whereas a mixed fracture is also observed in the $20 \mathrm{Cr}$ material, in which the shape of the particle is deformed from spherical to lanky particle at $873 \mathrm{~K}$, shown in Fig. 9(b). SEM fractographs in
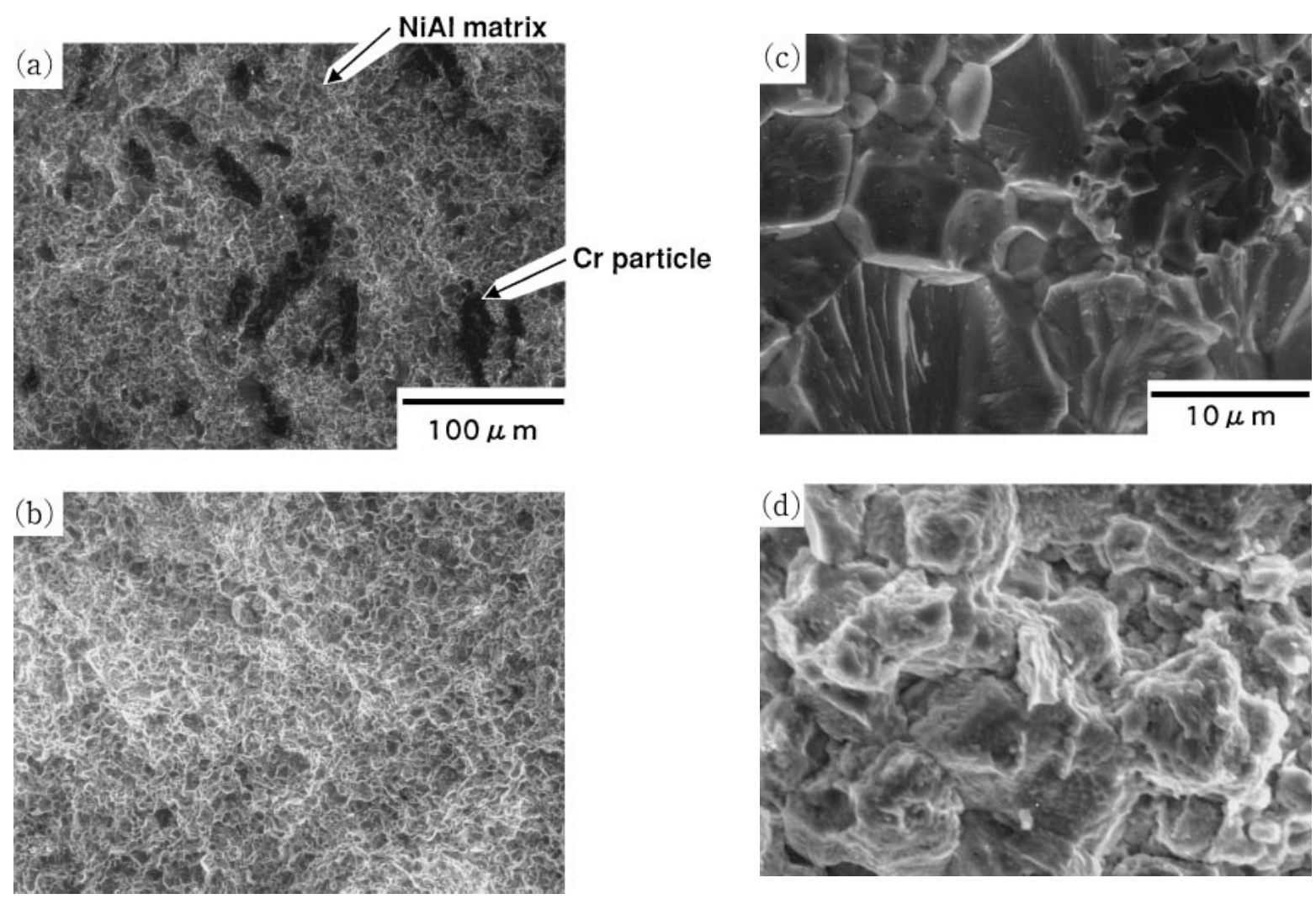

Fig. 8 Fractography of HIPed NiAl+10Cr; Macroscopic photos of (a) tested at $673 \mathrm{~K}$ and (b) $873 \mathrm{~K}$, and microscopic photos of (c) tested at $673 \mathrm{~K}$ and (b) $873 \mathrm{~K}$. 

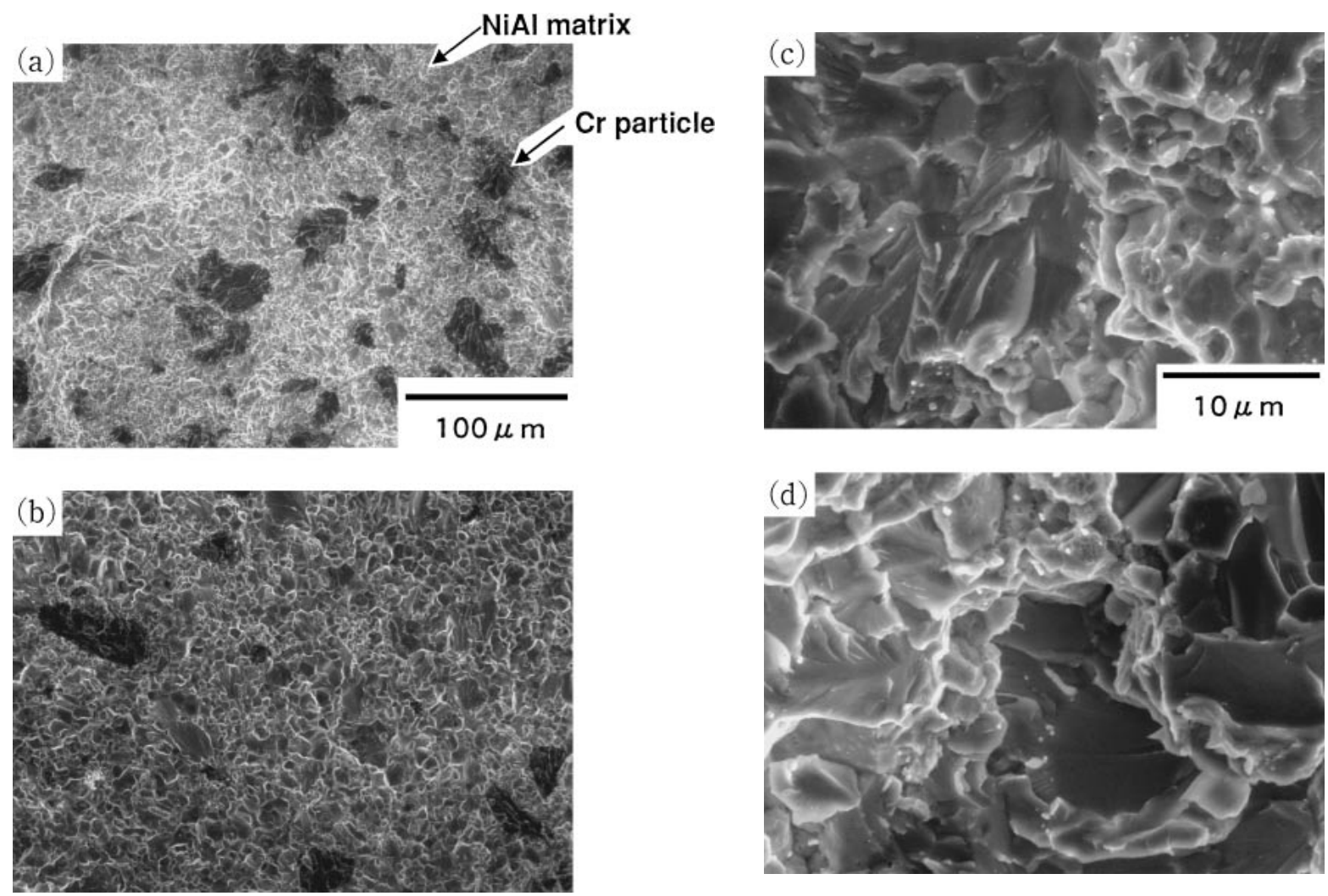

Fig. 9 Fractography of HIPed NiAl+20Cr; Macroscopic photos of (a) tested at $673 \mathrm{~K}$ and (b) $873 \mathrm{~K}$, and microscopic photos of (c) tested at $673 \mathrm{~K}$ and (b) $873 \mathrm{~K}$.

high magnification, shown in Figs. 8(c)-(d) and 9(c)-(d) reveal the details of the fracture surface of 10 and $20 \mathrm{Cr}$ materials. It is obvious that the brittle fracture occurred in inter- and transparticle in these materials tested at $673 \mathrm{~K}$, while ductile fracture occurred in both of materials at $873 \mathrm{~K}$, but a part of brittle fracture is still remained in $\mathrm{Cr}$ particles in 20Cr material.

This implied that the $\mathrm{Cr}$ addition less than 10 mass $\%$ in $\mathrm{NiAl}$ matrix is not enough which makes the powder particle boundaries become strong and contribute to improvement of the higher temperature strength. Whereas in higher $\mathrm{Cr}$ contents more than 20 mass $\% \mathrm{Cr}$, a sufficient strong interparticle bonding can be achieved in interparticle, especially in $20 \mathrm{Cr}$ material.

However, the area fraction of NiAl matrix contributed to high temperature strength is monotonically decreasing with increasing $\mathrm{Cr}$ additions, then the high temperature strength of $\mathrm{NiAl}+x \mathrm{Cr}$ decrease with increasing $\mathrm{Cr}$ additions more than 20 mass $\%$.

Tensile strength of RHIPed elemental materials measured at $673 \mathrm{~K}$ and $873 \mathrm{~K}$ are also shown in Fig. 7. Tensile strength of the RHIPed 25 and 30Cr elemental materials at higher temperature is a little bit lower that that of HIPed 20Cr prealloy material, but the degradation rate of high temperature strength of RHIPed $25 \mathrm{Cr}$ elemental material is almost the same value of that of $30 \mathrm{Cr}$ pre-alloy material. No remarkable difference in tensile strength is found between these materials with 25 and 30 mass $\% \mathrm{Cr}$ additions.

Therefore, most important factor, which could influence the ultimate tensile strength of the alloy with dispersive $\mathrm{Cr}$ particle, is well micro structural matching and interparticle bonding between matrix and dispersive particles. With the these results, it is concluded that HIP process can fabricate a very high ultimate strength materials at high temperature with the concentration of dispersive $\mathrm{Cr}$ particle, of which the best concentration could be exist between 15 to 20 mass $\%$ and not exceeds more than 20 mass $\% \mathrm{Cr}$.

\subsection{Effect of dispersive $\mathrm{Cr}$ particles on the ductility}

The uniform elongation of HIPed pre- and RHIPed elemental alloys tested at $673 \mathrm{~K}$ and $873 \mathrm{~K}$ was listed in Table 3 as a function of $\mathrm{Cr}$ addition. For the HIPed pre-alloy materials, the results reveal that plastic elongation is decreased with increasing $\mathrm{Cr}$ addition and good correlation is obtained between elongation and $\mathrm{Cr}$ concentration. In The RHIPed elemental alloys, the same dependency of elongation on $\mathrm{Cr}$ concentration is also found, but the elongation values obtained in RHIPed 25Cr elemental alloy is two times higher than that of HIPed $25 \mathrm{Cr}$ pre-alloy in the figure. Higher tensile ductility is facilitated by the presence of large mount of the disordered $\gamma$ phase and also a much homologous microstructure in matrix. ${ }^{14)}$ Therefore, a factor that could influence the homogeneous plastic deformation could be well-homogenized matrix microstructure and well development $\gamma / \gamma^{\prime}$ network structure, as shown in Fig. 4, which provides a very fine substructure size.

These results indicated that deformation feature of HIPed $\mathrm{NiAl}$ materials are very sensitive to the microstructure, that is, fineness of the microstructure of $\mathrm{NiAl}$ matrix is responsible for higher ductility at high temperatures, but ductility 
behavior is also strictly controlled by the Cr concentration. These results are certainly associated with characteristic microstructure, that is, interparticle bonding between dispersive $\mathrm{Cr}$ particle and $\mathrm{NiAl}$ matrix developed during hipping process. As far as this point is concerned, most important factor is best plastic deformation matching between dispersive $\mathrm{Cr}$ particle and $\mathrm{NiAl}$ matrix. With the result of micro hardness measurement, as shown in Table 3, hardness mismatch between dispersive $\mathrm{Cr}$ particle and NiAl matrix, which will influence the inhomogeneous plastic deformation, can be observed in the as-hipped materials, which the hardness values of $\mathrm{Cr}$ particle is normally lower than that of $\mathrm{NiAl}$ matrix. Thus $\mathrm{Cr}$ particles behave more good ductility than that of NiAl matrix under the tensile stress and then large elongation mismatching occurred in interparticle, which induces micro cracking in the materials.

In present experiments, the Ductile-Brittle TransitionTemperature (DBTT) is defined by the temperature at which adequate tensile ductility of more than $0.2 \%$ is obtained during tensile strength tests. From the data shown in Table 3, the DBTTs of almost of these materials are not observed at less than $673 \mathrm{~K}$, whereas adequate tensile elongation are only found at $873 \mathrm{~K}$ in HIPed $20 \mathrm{Cr}$ pre-alloy and RHIPed $25 \mathrm{Cr}$ elemental alloy, which are high tensile strength and high ductility material, respectively. These results indicated that the lower temperature ductility as can be achieved by the two factors, that is, high strength due to well fined microstructure provided by $\gamma / \gamma^{\prime}$ network found in elemental materials.

\section{Conclusions}

The present study mainly concerns the effect of dispersive $\mathrm{Cr}$ particles on the microstructure and mechanical properties of NiAl pre- and elemental alloyed intermetallics fabricated by the Hot Isostatic Press (HIP) and Reactive HIP (RHIP) techniques.

The effect of dispersed Cr particle on mechanical properties of HIPed NiAl materials is more complicated. For the HIPed pre-alloy materials, the hardness mismatching between matrix and $\mathrm{Cr}$ particles is found in the lower tensile strength materials, while higher strength at high temperature can be achieved by the materials with good micro structural matching between matrix and dispersed $\mathrm{Cr}$ particles.

Plastic elongation of pre-alloyed materials are decreased with increasing $\mathrm{Cr}$ concentration, but compared to the elemental materials, very high ductility can be observed in elemental materials. These results are associated with the deformation mismatching between fine homogeneous matrix structure and $\mathrm{Cr}$ particles.

Higher tensile strength and high ductility at higher temperatures are facilitated by the existence of large amount of the dispersive $\mathrm{Cr}$ particles. Moreover, it must be emphasized that the interparticle bonding and micro structural mismatching have to be treated as very important factors in determining mechanical properties of HIPed materials.

SEM examination of the fracture surfaces of the low $\mathrm{Cr}$ concentration materials suggested a transition from transparticle fracture to interparticle fracture of dispersive $\mathrm{Cr}$ particles with increasing testing temperature.

In conclusion, our results indicated that dispersive $\mathrm{Cr}$ concentration in $\mathrm{NiAl}$ materials should not exceed more than 20 mass $\%$ in mechanical properties, and very good ductility can be achieved by elemental materials consolidated by reactive hot isostatic press technique.

\section{REFERENCES}

1) S. Ishiyama and M. Muto: PWR-Vol. 34, 1999 Joint Power Generation Conference Vol. 2 ASME, (1999) 707-714.

2) Y. Muto, S. Ishiyama, T. Tanuma, S. Kisibe and I. Matumoto: Proc. Of Int. Gas turbine Congress 1999 Kobe, Vol. I, (1999) 313.

3) Y. Muto, S. Ishiyama, A. Inomata, T. Kisibe, K. Minatuki, I. Matumoto and F. Levet: Proc. Of ASME Turbo Expo 2001, (2001) 8-14.

4) K. H. Hahn and K. Vedula: Scr. Metall. 23 (1989) 7-12.

5) D. R. Pank, M. V. Nathal and D. A. Koss: J. Mater. Res. 5 (1990) $942-$ 949.

6) M. Takeyama and C. T. Liu: J. Mater. Res. 5 (1990) 1189-1196.

7) E. P. George and C. T. Liu: J. Mater. Res. 5 (1990) 754-762.

8) R. R. Bowman, R. D. Noebe, S. V. Raj and I. E. Locci: Meta. Trans. A 23A (1992) 1493-1507.

9) A. U. Seybolt: Tran. ASM 59 (1966) 860-871.

10) D. E. Alman and N. S. Stoloff: Int. J. of Powder Metallurgy 27 (1991) 29-32.

11) S. C. Iha and R. Ray: J. Mater. Sci. Lett. 7 (1988) 285-261.

12) J. I. Walters and H. E. Cline: Metal. Trans. 4 (1973) 33-41.

13) K. E. Mohamed, D. Stöver and H. P. Buchkremer: Powder Metallurgy, World Congress, San Franciso, (1992) 142-151.

14) L. Z. Zhuang, I. Majewska, R. Vetter, T. Anel and D. Stover: 4th Int. Conf. on isostatic Pressing, Stanford-upon-Avon, 22-1 (1990) 965-974.

15) S. Ishiyama, M. Eto, H. Ugachi and K. Fukaya: Intermetallic compounds Structure and Mechanical properties, Proc. 6th Japan. Inst. Met. int. Symp., Japan. Inst. Met., Sendai, (1991) 609-610. 